\title{
Quantitative trait loci for upper thermal tolerance in outbred strains of rainbow trout (Oncorhynchus mykiss)
}

\author{
GUY M. L. PERRY*†, ROY G. DANZMANN $\dagger$, MOIRA M. FERGUSON $\dagger$ \\ \& JOHN P. GIBSON: \\ $\uparrow$ Department of Zoology, University of Guelph, Guelph, ON, CANADA N1G 2W1 and $\ddagger$ Genetics and Genomics, \\ International Livestock Research Institute, PO Box 30709, Nairobi, Kenya
}

\begin{abstract}
The expression of three putative QTL for upper thermal tolerance (UTT) was examined in two strains of outbred rainbow trout unselected for this trait using simple-sequence repeat (SSR; microsatellite) markers associated with UTT in backcrosses of lines selected on this trait. Two-way diallel lots in the third generation of an outbred pedigree were exposed to an acute thermal challenge. QTL detection was performed separately by each second-generation parent within each diallel lot, incorporating the effects of full sib families and correlated traits. Inheritance of different alleles at the SSR Ssa20.19NUIG from the sire 93-32-1 was strongly associated with the thermal tolerance of his half sib progeny, explaining $7.5 \%$ of their phenotypic variance in this trait. A hierarchical linear model incorporating allelic inheritance from all four grandsires of the experimental diallels (in addition to family specific and covariate trait effects) was also used to detect associations between the SSR and thermal tolerance in their third-generation grandprogeny. Ssa20.19NUIG was strongly associated with thermal tolerance in the grandprogeny of the grandsire $\mathrm{G}_{0} \mathrm{SVM} 2$. The generally stronger markertrait associations found in male parents may be partially due to reduced chromosomal recombination rates in male salmonids compared to females. These results indicate the effects of a QTL on a fitnessrelated trait in unselected populations of rainbow trout.
\end{abstract}

Keywords: grandsire model, outbred, QTL, rainbow trout, stress, thermal tolerance.

\section{Introduction}

In aquatic ectotherms, environmental temperature fluctuations may have lethal effects at the extremes of environmental stress and minor temperature fluctuation may cause severe physiological disruption (see Wood \& McDonald, 1997). It appears likely that such stress is particularly relevant for stenothermic ectotherms (Johnston \& Bennett, 1996). The impact of acute thermal stress may also be compounded in the aquatic environment by the ability to physiologically respond to correlated changes in other water quality parameters, such as dissolved oxygen and unionized ammonia (Pennell \& Barton, 1996). A number of different molecular chaperones appear to be involved in the thermal stress in fish (Iwama et al., 1998), suggesting a polygenic architecture for this trait. Conventional quantitative genetic theory has been used in salmonid fish (Osteichthyes: Salmonidae) to explore the heritabil-

\footnotetext{
*Correspondence. E-mail: gperry@uoguelph.ca
}

ity of the overall stress response (Pottinger \& Pickering, 1997) and the response to specific stressors (Fevolden et al., 1999).

Backcrosses or $F_{2}$ intercrosses of hybrids between lines with strong phenotypic divergence due to artificial selection have been used to detect QTL for complex physiological traits in agricultural (Knott et al., 1999) and laboratory (Cheverud et al., 1996) species. For example, backcrosses of phenotypically divergent rainbow trout (Oncorhynchus mykiss) lines have been used to detect QTL for upper thermal tolerance (UTT) (Jackson et al., 1998; Danzmann et al., 1999) and spawning time (Sakamoto et al., 1999). With the exception of cattle (see Stone et al., 1999), there has been little effort directed at QTL detection in outbred populations (see Poompuang \& Hallerman, 1996). While theory predicts maximal power for QTL detection in intercrosses of selected lines (see Liu, 1998; Lynch \& Walsh, 1998), the genomic constitution of such groups cannot be representative of wild populations, and domesticated salmonid populations derived from intensive single-trait 
selection are generally uncommon (Poompuang \& Hallerman, 1996). The detection of QTL for certain traits in outbred populations might have greater relevance both to natural selection and artificial improvement, especially when taken in context of their effects against other sources of genetic variation (i.e. specific genetic background, parental effects, etc.). Suggestive evidence of QTL for growth (Gross \& Nilsson, 1999) and disease resistance (Palti et al., 1999) exists in commercial salmonids but lacks documented pedigree information.

The objective of this study was to assess if previously reported associations between allelic variants at three SSR loci (Ssa20.19NUIG, Ssa14DU and Omy325UoG) (see refs in Jackson et al., 1998; Danzmann et al., 1999) and upper thermal tolerance in divergently selected lines for this trait were also detectable in unselected outbred rainbow trout. These SSR loci are linked to putative upper thermal tolerance QTL in backcrosses of the selected lines used by Jackson et al. (1998) and Danzmann et al. (1999). We verify the presence of a strong association between one of the putative QTL markers (Ssa20.19NUIG) and thermal tolerance in outbred fish. This marker was previously reported to have the strongest association with thermal tolerance among several markers tested. The use of a multigenerational grandsire QTL model incorporating phenotypic, allelic and pedigree information also supported this finding.

\section{Materials and methods}

Two commercial strains of rainbow trout, Spring Valley (SV) (Spring Valley Trout Farm Ltd, Petersburg ON) and Rainbow Springs (RS) (Rainbow Springs Trout Farm, Thamesford, ON) were used in this study. Two first-generation $\left(\mathrm{G}_{0}\right) \mathrm{SV}$ and RS 'grandsires' $\left(\mathrm{G}_{0} \mathrm{SVM} 1\right.$, $\mathrm{G}_{0} \mathrm{SVM} 2, \mathrm{G}_{0} \mathrm{RSM} 1$ and GoRSM2) were mated within strain to 12 and 13 grandams, respectively, creating 35 pure-strain second-generation $\left(\mathrm{G}_{1}\right)$ ('parental') families (Table 1). These fish were reared at the Ontario Ministry of Agriculture, Food and Rural Affairs (OMAFRA) Alma Aquacultural Research Station (AARS) (Alma, ON) until the 1996-97 breeding season when they were bred to form $112 \times 2$ diallel lots (44 inter- and intrastrain families). These were reared either at AARS or in the Axelrod Building Wet Lab (AWL), Department of Zoology, University of Guelph (Guelph, ON). Rearing was conducted in either $0.3 \mathrm{~m}$ tanks (AARS), washbasins (3.9 L/family) (AWL) or in subdivided sections (anterior to posterior from water inflow) of a 12.4-L raceway (3.1 L/family) (AWL). Raceway-reared lots were each housed in a single raceway, with each of the four families in one of the sequential units. Family order was random within each raceway.
At 8-10 months postfertilization, 48-96 individuals per family (from each of the four families in each diallel lot) were acclimated for approximately two weeks at $10^{\circ} \mathrm{C}$ in the Hagen Aqualab, University of Guelph. The fish were then subjected by lot to a thermal challenge where water temperature was raised from $10^{\circ} \mathrm{C}$ to $25.7^{\circ} \mathrm{C}$ (critical thermal maximum (CTmax) for $10^{\circ} \mathrm{C}$ acclimated rainbow trout) (Bidgood, 1980; Currie et al., 1998), over approximately one hour and maintained at that temperature thereafter. Temperature readings were taken throughout using a pair of inline sensors in the experimental tank. Oxygen saturation remained above $80 \%$ for the duration of the experiment. Effective time (ET) (Fry, 1971) of survival for individual fish was taken to be the time elapsed at CTmax when fish were unable to maintain equilibrium (see Jackson et al., 1998). Wet weight (FW, grams) and fork length (FL, length in millimetres from anterior tip of the snout to the fork in the caudal fin) were also recorded. Since variability in rate of temperature increase between experiments may have affected estimates of ET between lots, survival data was converted into cumulative exposure in degree $\cdot$ minutes $(\mathrm{d} \cdot \mathrm{m})$ by summing all differences between the acclimation temperature $\left(10^{\circ} \mathrm{C}\right)$ and the experimental temperature at each minute until the loss of equilibrium, considered here as upper thermal tolerance (UTT). ET was considered in comparison with previous work (Jackson et al., 1998; Danzmann et al., 1999).

DNA was extracted using a modification of Bardakci \& Skibinski (1994) or the IsoQuick nuclear DNA extraction kit (ORCA Research). Variability at three SSR loci (Omy325UoG, Ssa14DU and Ssa20.19NUIG) was detected (see Jackson et al., 1998 for a general protocol) using the polymerase chain reaction (PCR) with radioactive end-labelled $\left(\gamma \mathrm{P}^{33}\right)$ primers. PCR products were separated in $6 \%$ denaturing polyacrylamide gels with fragment size determined using M13 sequencing ladder. Genotypes were manually scored using autoradiographs produced with Kodak BioMax film.

General linear modelling (PROC GLM; SAS Institute, 1996) was used to correct the effect of sequential ordering (by distance from inflow) of families in raceway $G_{2}$ lots. Health and gross physiological state may be indicated by various growth traits (Pennell \& Barton, 1996), such as wet weight (FW), fork length (FL) and condition factor $(\mathrm{K})$ (the residual of $\log (\mathrm{FW})=$ $\log (\mathrm{a})+\beta \log (\mathrm{FL})($ Pennell and Barton, 1996)). Since FL and FW were highly correlated $(\beta=0.891-0.988)$ and collinear in each pair of half sib families (variance inflation factor (VIF) (SAS Institute, 1996) > 10.0), only FL was used as a covariate in QTL analysis. This trait was strongly associated with UTT in previous work (Jackson et al., 1998). K was not collinear with either FL 


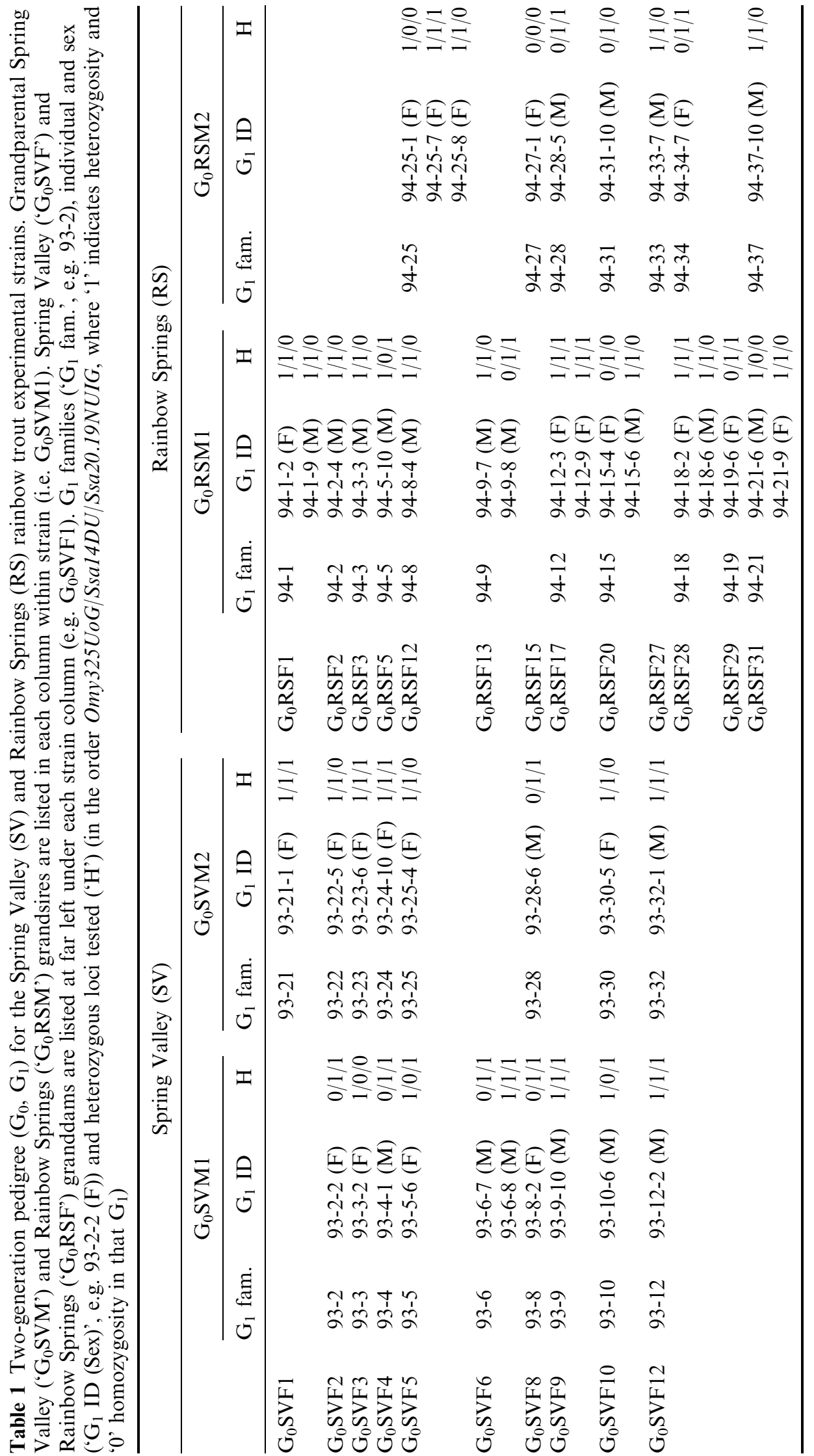

(c) The Genetics Society of Great Britain, Heredity, 86, 333-341. 
or FW in any of the half-sib families (correlation with FL: $0.220-(-0.491)$, VIF < 10.0; correlation with FW: $0.601-(-0.248)$, vIF $<10.0)$. FL and $\mathrm{K}$ were evaluated for inclusion as covariates in QTL modelling using sequential backward elimination ( $\alpha$ for removal 0.05) on a fully saturated model within the half-sib progeny of each a common parent (SAS Institute, 1996).

Inheritance from each common $\mathrm{G}_{1}$ parent was tested separately at each locus (PROC GLM, SAS Institute, 1996) following the model,

$\mathrm{y}_{\mathrm{ik}}=\mu+\alpha_{\mathrm{i}}+\lambda_{\mathrm{j}}+\alpha_{\mathrm{i}} \lambda_{\mathrm{j}}+\beta_{\mathrm{m}} \mathrm{C}_{\mathrm{mk}}+\varepsilon_{\mathrm{ijk}}$,

where $\mu$ is the overall mean, $y_{i k}$ is the UTT of $G_{2}$ individual $\mathrm{k}$ from one of two half-sib families inheriting marker allele $i$ at the locus of concern from the common $G_{1}$ half-sib parent $i, \alpha_{i}$ is the fixed effect of allelic inheritance at a given marker locus from the common $G_{1}$ sire or dam, $\lambda_{j}$ is the fixed effect of the non-common $G_{1}$ parent $i$ in the cross, $\alpha_{i} \lambda_{j}$ is the interaction of alleles from the common $G_{1}$ parent with the background of the non-common parents, $\beta_{\mathrm{m}}$ is the regression coefficient for each of $\mathrm{m}$ covariates not rejected by stepwise backwards regression, $\mathrm{C}_{\mathrm{mk}}$ is the value of covariate $m$ for $G_{2}$ half sib $k$ and $\varepsilon_{i j k}$ is the random residual. Where residuals from QTL modelling were non-normally distributed (detected using the Shapiro-Wilk W-statistic (Shapiro \& Wilk, 1965)) data were transformed using a likelihood-based macro (BoxGLM; M. Friendly, York University) to normalize residuals before reanalysis. Significance of locus effects were adjusted with simultaneous Bonferroni correction (Rice, 1989) by the total number of independent tests run, resulting in a significance threshold of $P=0.05 / 82$ independent $\mathrm{G}_{2}$ half-sib tests $=0.0006$, excluding cases where it was not possible to differentiate allele identity. Missing data and unassignable genotypes were ignored at all levels of analysis.

The existence of QTL for UTT in the $\mathrm{G}_{2}$ grandprogeny of each of the four $\mathrm{G}_{0}$ grandsires was tested using a modified grandsire model of the form

$\mathrm{y}_{\mathrm{ijgk}}=\mu+\alpha_{\mathrm{i}}+\alpha_{\mathrm{i}}\left(\gamma_{\mathrm{j}}\right)+\gamma_{\mathrm{j}}\left(\varphi_{\mathrm{g}}\right)+\beta_{\mathrm{FL}} \mathrm{X}_{\mathrm{FL}}+\beta_{\mathrm{K}} \mathrm{X}_{\mathrm{K}}+\varepsilon_{\mathrm{ijgk}}$

where $y_{i j g k}$ is the UTT of $G_{2}$ grandprogeny $k, \alpha_{i}$ is the effect of allele $i$ from the $\mathrm{G}_{0}$ grandsire at the SSR locus, $\alpha_{i}\left(\gamma_{j}\right)$ is the effect of the $G_{1}$ sire or dam of $G_{2}$ individual $k$ nested within the allele received from that grandsire, $\gamma_{\mathrm{j}}\left(\varphi_{\mathrm{g}}\right)$ is the nested effect of the non-common $\mathrm{G}_{1}$ parent within the common $\mathrm{G}_{1}$ parent (i.e. full sib family-specific effects) in each pair of half sib families, $\beta_{\mathrm{FL}} \mathrm{X}_{\mathrm{FL}}$ and $\beta_{\mathrm{K}} \mathrm{X}_{\mathrm{K}}$ are the effects of covariates $\mathrm{FL}$ and $\mathrm{K}$ and $\varepsilon_{\mathrm{ijgk}}$ is the random residual. BoxGLM was used to provide the optimal transformation of UTT data when nonnormality in the model residuals was detected with the Kolmogorov-Smirnov D-statistic (Steel \& Torrie, 1980). This test was used because of the large number of $G_{2}$ grandprogeny per grandsire. Significance thresholds were corrected by the total number of tests, excluding the three loci that were homozygous in the four grandsires $(P=0.05 / 9=0.00556)$. Missing data and cases where allelic inheritance from the grandsires could not be assigned with certainty in the $G_{2}$ lots were excluded from analysis. Scheffe tests (in SAS Institute, 1996) were used to identify significant differences between UTT means for alleles from $\mathrm{G}_{0}$ sires in their $\mathrm{G}_{2}$ grandprogeny. Each possible form of inheritance at each locus from the $\mathrm{G}_{0}$ grandsires, including not inheriting either allele, were included as factor states in the allelic term.

\section{Results}

Family position within raceway had significant effects on UTT $\left(F_{3,876}=22.20, \quad P=0.0001\right)$ and $\mathrm{K}$ $(P=0.0005)$ but not on FL $(P=0.2716)$ or FW $(P=0.0639)$. Mean UTT of raceway-reared families increased within increasing distance downstream from the inflow $\left(\mu_{\text {nearest to inflow }}(1230.8 \mathrm{~d} \cdot \mathrm{m})=\right.$ $\mu_{2 \text { nd nearest }}(1221.7 \mathrm{~d} \cdot \mathrm{m})<\mu_{2 \text { nd furthest }}(1408.3 \mathrm{~d} \cdot \mathrm{m})$ $\left.<\mu_{\text {furthest from inflow }}(1612.8 \mathrm{~d} \cdot \mathrm{m})\right)$, while $\mathrm{K}$ of fish reared in the nearest $\left(\mu=0.993 \log \left(\mathrm{g} \cdot \mathrm{mm}^{-1}\right)\right)$ and furthest $\left(\mu=0.989 \log \left(\mathrm{g} \cdot \mathrm{mm}^{-1}\right)\right)$ cells were significantly lower than those in the middle two cells. UTT and $\mathrm{K}$ were adjusted for these effects. The correlation of FL and K with UTT depended strongly on half sib family pair. Departure of UTT data from normality, measured by non-normality in the model residuals $(P<0.05)$ (Shapiro \& Wilk, 1965) varied with the $\mathrm{G}_{1}$ parent and the locus under consideration (see Table 2). BoxGLM was used to determine the best normalizing transformation (on the scale of $\mathrm{UTT}^{2}$ to $\mathrm{UTT}^{-2}$ ) where UTT was non-normally distributed in half sib families; only in one instance could an appropriate transformation not be found (see Table 2).

Significant differences in UTT were detected between the $G_{2}$ progeny of $G_{1}$ sire 93-32-1 (a son of grandsire $\left.\mathrm{G}_{0} \mathrm{SVM} 2\right)$ inheriting different alleles at Ssa20.19NUIG from that sire $(P=0.0001)$ (Table 2$)$. Thermal tolerance of half-sibs inheriting different alleles at this locus was 2130.6 and $1836.5 \mathrm{~d} \cdot \mathrm{m}$ or 79.5 and $61.0 \mathrm{~min}$ of effective survival time (ET) at the CTmax, explaining approximately $7.5 \%$ of phenotypic variance in each of these traits. Although several tests were significant at a priori levels with inheritance at all three loci explaining a small to moderate proportion $(1.52-7.50 \%)$ of phenotypic variance in UTT, no significant additive or interactive 


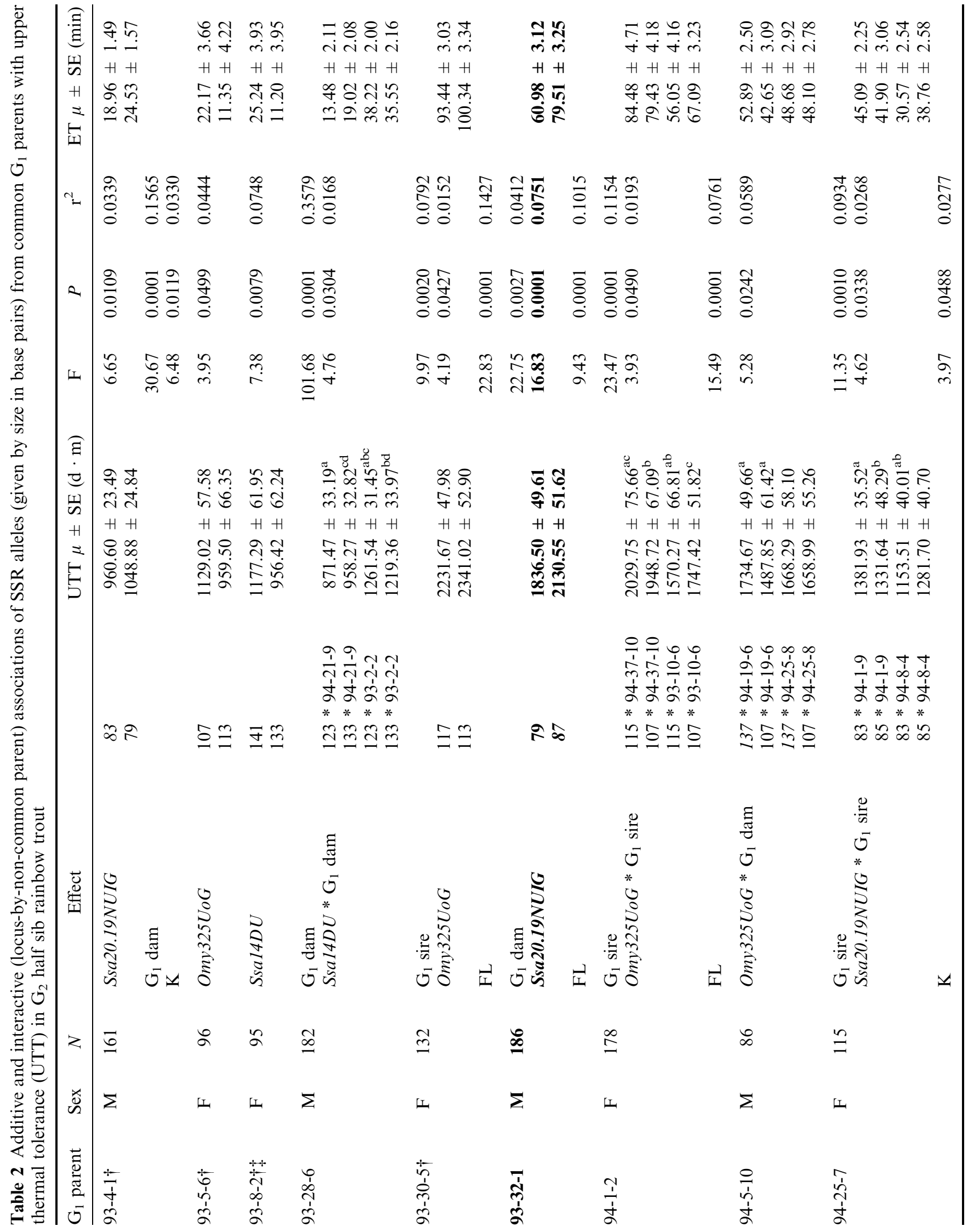

(C) The Genetics Society of Great Britain, Heredity, 86, 333-341. 


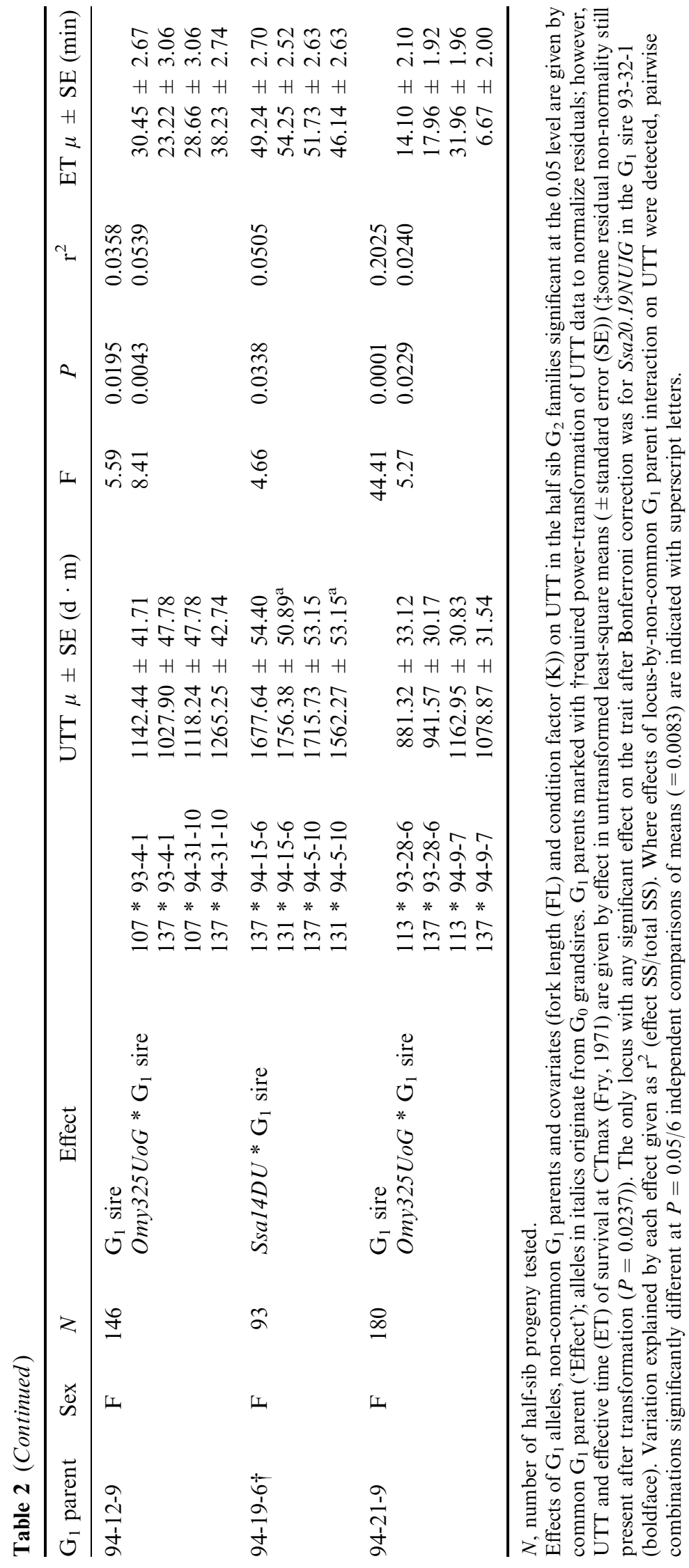

(c) The Genetics Society of Great Britain, Heredity, 86, 333-341. 
effects of the genomic regions marked by these SSR on UTT were detected for any other comparison after Bonferroni correction (Table 2). However, there was evidence of significant pairwise differences between particular combinations of alleles from common $\mathrm{G}_{1}$ parents and non-common parental backgrounds in some half sib groups, some of which were considerable $(P=0.0001)$. Omy325UoG tended to be more frequently associated with UTT in $\mathrm{G}_{1}$ dams and Ssa20.19NUIG in $\mathrm{G}_{1}$ sires; the strength of marker-UTT associations appeared to be generally greater in male parents than in females overall, particularly at Ssa20.19NUIG (Table 2).

UTT was non-normally distributed in most $G_{0}$ grandsire tests even after optimal transformation $(P<0.05)$ (although Box plots of transformed grandprogeny data appeared normal); the best possible transformation of UTT was used in grandsire QTL modelling. In the grandprogeny of $\mathrm{G}_{0} \mathrm{SVM} 2$, UTT was strongly associated with inheritance at Ssa20.19NUIG from him (Table 3; Fig. 1). Ssa20.19NUIG explained close to $1 \%$ of variation in the UTT of $\mathrm{G}_{0} \mathrm{SVM} 2$ 's grandprogeny, which was considerably less than the nesting of non-common $G_{1}$ parent within common $G_{1}$ parent (i.e. full sib familial effect). FL also had a significant effect on UTT in the grandprogeny of $\mathrm{G}_{0} \mathrm{SVM} 2$ (Table 3). Scheffe tests for differences in UTT means indicated that grandprogeny inheriting allele 87 at Ssa20.19NUIG from $\mathrm{G}_{0}$ SVM2 had a much higher thermal tolerance than those inheriting allele 83 or neither of the above alleles, supporting the findings from the half sib progeny of 93-32-1, which was a son of $\mathrm{G}_{0} \mathrm{SVM} 2$ (see also Fig. 1). A significant association between UTT and $O m y 325 U o G$ nested by $\mathrm{G}_{1}$ parent was also found in the grandprogeny of $\mathrm{G}_{0} \mathrm{SVM} 1$ $\left(F_{1,1274}=2.93 ; P=0.0324\right)$, although no main effects of this locus were observed $(P=0.2027)$. However, main effects of $S s a 14 D U$ on UTT were observed in the grandprogeny of $\mathrm{G}_{0} \mathrm{SVM} 1\left(F_{1,1264}=3.15 ; P=0.0432\right)$. Neither of these general associations was significant after Bonferroni correction, however, and no other associations of the SSR loci with UTT were found $(P>0.05)$.

\section{Discussion}

Our results indicate the linkage of an SSR locus (Ssa20.19NUIG) with a quantitative trait (upper thermal tolerance) in outbred rainbow trout. Previously, strong marker-trait associations (involving this marker) had only been reported in backcrosses of highly selected lines (Danzmann et al., 1999). Inheritance at this locus explained a considerable proportion $(7.5 \%)$ of phenotypic variation in upper thermal tolerance in the progeny of an outbred $\mathrm{G}_{1}$ sire (93-32-1) approximating the definition of a 'major' QTL (Lynch \& Walsh, 1998), although this experimental design was not able to separate the true estimate of effect for this QTL from marker-QTL recombination fraction. The association of Ssa20.19NUIG with UTT in this sire was supported by the use of a two-generational grandsire model in $\mathrm{G}_{0} \mathrm{SVM} 2$ including genotypic and phenotypic information in all of his $\mathrm{G}_{2}$ grandprogeny.

Differences in the recombination rates observed between male and female salmonids (Johnson et al., 1987; Sakamoto et al., 2000) may help to explain the differences in observed marker/trait associations by $\mathrm{G}_{1}$ sex and marker. Recombination rates in male salmonids appear to be higher towards telomeric regions than in centromeric regions of the chromosome, whereas recombination events appear uniformly distributed throughout the length of the female chromosome

Table 3 Associations of grandparental alleles from $\mathrm{G}_{0}$ SV grandsire $2\left(\mathrm{G}_{0} \mathrm{SVM} 2\right)$ at Ssa20.19NUIG with UTT in outbred $\mathrm{G}_{2}$ grandprogeny of rainbow trout

\begin{tabular}{|c|c|c|c|c|c|c|c|c|}
\hline $\mathrm{G}_{0}$ sire & $N$ & Effect & Value & $\beta$ & UTT $\mu \pm \mathrm{SD}(\mathrm{d} \cdot \mathrm{m})$ & $\mathrm{F}$ & $P$ & $\mathrm{r}^{2}$ \\
\hline \multirow[t]{7}{*}{ SVM2 } & 1018 & Ssa20.19NUIG & 87 & 0.00 & $1821.46 \pm 659.88$ & 9.30 & 0.0001 & 0.0079 \\
\hline & & & 83 & -884.97 & $1206.49 \pm 430.47$ & & & \\
\hline & & & Neither & -281.25 & $1415.59 \pm 590.25$ & & & \\
\hline & & $\begin{array}{l}\text { Ssa20.19NUIG } \\
\quad \text { (common } \mathrm{G}_{1} \text { parent) }\end{array}$ & & & & 0.07 & 0.9333 & 0.0001 \\
\hline & & $\begin{array}{l}\text { Common } \mathrm{G}_{1} \text { parent } \\
\quad \text { (non-common parent) }\end{array}$ & & & & 10.12 & 0.0001 & 0.0341 \\
\hline & & FL & & 3.48 & & 24.67 & 0.0001 & 0.0104 \\
\hline & & $\mathrm{K}$ & & -125.01 & & 0.59 & 0.4421 & 0.0003 \\
\hline
\end{tabular}

Estimates of effect for allelic inheritance at Ssa20.19NUIG and covariate terms ( $\beta$ ) determined using PROc GLM (SAS Institute, 1996). Variation explained by each effect given as $\mathrm{r}^{2}$ (effect SS/total SS). All UTT means and standard deviations (SD) for Ssa20.19NUIG allelic states were significantly different at $P=0.05 / 3$ independent pairwise comparisons of means $(=0.0167)$. Maximum power transformation $\left(\mathrm{UTT}^{0.4}\right.$ ) used to determine $\mathrm{F}$ ratios, $P$-values and $\mathrm{r}^{2}$. Nested terms given as 'main effect (effect nested within main effect)'.

(C) The Genetics Society of Great Britain, Heredity, 86, 333-341. 


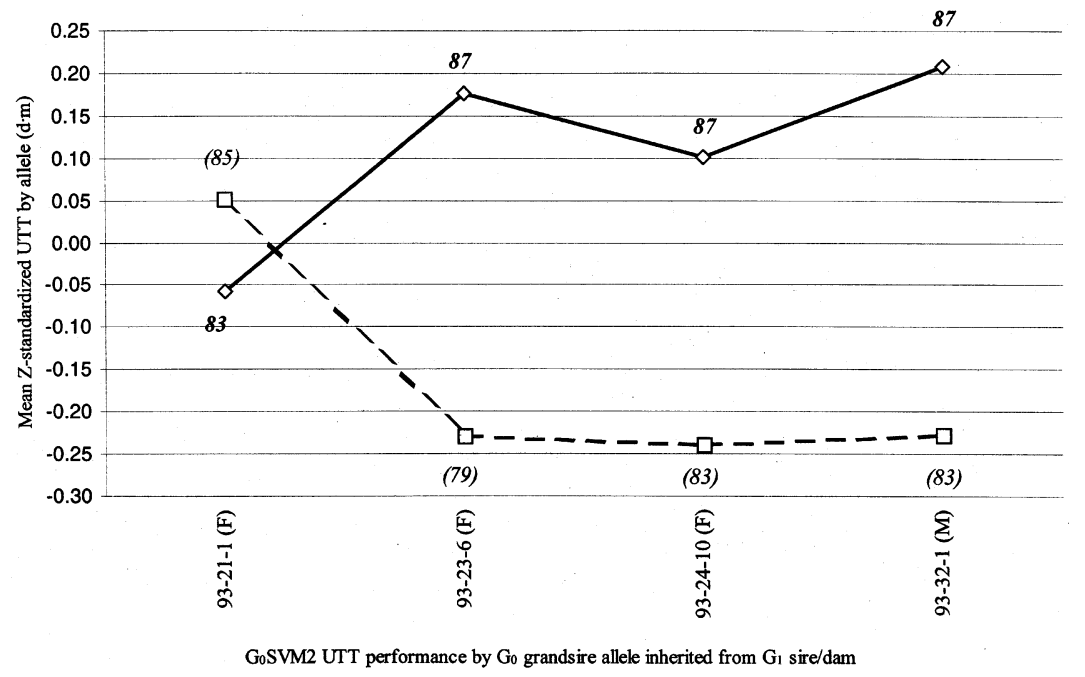

Fig. 1 Mean Z-standardized upper thermal tolerance (UTT) of second generation $\left(\mathrm{G}_{2}\right)$ grandprogeny of rainbow trout inheriting different alleles (83 or $87 \mathrm{bp}$; italics, joined by solid line) from Spring Valley grandsire $\mathrm{G}_{0} \mathrm{SVM} 2$. Alleles originating from $G_{0}$ granddams are given (no italics, joined by dashed line) for comparison. Allelic identity in $\mathrm{G}_{1}$ dams 93-22-5, 93-25-4 and 93-30-5 and $\mathrm{G}_{1}$ sire 93-28-6 was not determinable; results from these individuals are not included.
(Sakamoto et al., 2000). Block segregation of large chromosomal regions is thus common in males for most of the intertelomeric regions of a linkage group. This suggests both an increase in the probability of detecting QTL in centromeric regions and a limit on the usefulness of telomeric markers for QTL detection in sires. Omy325UoG (linkage group B) and Ssa20.19NUIG (linkage group S) appear to be telomeric while Ssa14DU (linkage group D) is centromeric (Danzmann et al. unpublished; Sakamoto et al., 2000). While the higher frequency of $\mathrm{Omy} 325 \mathrm{UoG} / \mathrm{UTT}$ associations in female $\mathrm{G}_{1}$ parents may suggest increased female-specific marker/QTL linkage, stronger associations of UTT with Ssa14DU would have been expected in male parents if pronounced QTL effects were present at this locus. Ssa20.19NUIG, while possibly telomeric, appeared to have strong evidence for QTL effects over multiple generations in male parents, which could indicate tight marker-QTL linkage in this region.

The amount of variation in thermal tolerance ascribed to Ssa20.19NUIG and overall tolerance of fish in the present study were both considerably less than in the backcross (BC) families studied previously (Jackson et al., 1998; Danzmann et al., 1999). The genetic background of the different groups might be responsible for a proportion of the difference between thermal tolerance in the $\mathrm{BC}$ and outbred families. Given the diverse sources of the $\mathrm{BC}$ families and the extremity of divergent selection on them (Ihssen, 1986), QTL segregants from the hybrid male of Jackson et al. (1998) and Danzmann et al. (1999) should have considerably greater mean effect than would be found in unselected populations. UTT variance in the BC families was roughly an order of magnitude greater than in the outbred groups (Perry et al. unpublished). Mean ET in the progeny of the lowline BC dam crossed to the hybrid male (Jackson et al., 1998; Danzmann et al., 1999) was roughly comparable to the outbred half-sibs in this work, suggesting little previous selection for increased thermal tolerance in the commercial strains. Sire and dam effects on UTT in the outbred half sibs also appeared to be considerably stronger than putative SSR-linked QTL, suggesting the greater role of polygenic background than these QTL in across-full sib family comparisons, although Ssa20 $19 N U I G$ seemed to be an exception to the above.

The fish stress response is common to a number of environmental stressors including various pathogens (Iwama et al., 1998), and the role of stress response candidates such as heat shock proteins (hsp) in transmembrane transport and protein conformation is well known (Morimoto et al., 1994). Improvement in upper thermal tolerance might result in correlated improvement in generalized stress tolerance and/or basal physiological efficiency for a number of traits including upper thermal tolerance. Moreover, the extensive use of sea-cages in salmonid aquaculture may result in the exposure of valuable production cohorts and/or broodstock to diurnal and seasonal environmental fluctuations, in which the direct and indirect consequences of acute thermal stress may be particularly serious due to the reduced oxygen carrying capacity of seawater (Pennell \& Barton, 1996). Acute diurnal temperature fluctuation may also have diverse and serious impacts on the physiology of aquatic ectotherms, and may be a major driving force in their evolution (Johnston \& Bennett, 1996; Wood \& McDonald, 1997). Previous work has identified linkage between the heat shock protein (hsp) gene heat-shock cognate $71(h s c 7 l)$ and One14ASC (Sakamoto et al., 2000), a marker associated with UTT in the progeny of the low-line dam in the backcross families of Danzmann et al. (1999). A more complete comprehension of the genetic architecture of thermal tolerance (including those for correlated traits) might result in a clearer understanding of the 
evolutionary role and commercial significance of these genomic regions in thermal stress fitness and selection on this trait.

\section{Acknowledgements}

We would like to thank the personnel at AARS (M. Burke, D. Bevan, M. Kirk, N. MacBeth) and the Hagen Aqualab (R. Frank, P. Matsumoto) for their assistance with rearing and experimental facility construction. A. Fishback, T. Jackson and T. Sakamoto provided invaluable technical advice. A number of others assisted with rearing and experimentation including H. Allen, C. Cameron, R. Jones, L. Perry and K. Mandzuk. This research was supported by funds from NSERC (Canada).

\section{References}

BARDAKCI, F. AND SKIBINSKI, D. O. F. 1994. Application of the RAPD technique in tilapia fish: species and subspecies identification. Heredity, 73, 117-123.

BIDGOOD, B. F. 1980. Temperature Tolerance of Hatchery Reared Rainbow Trout Salmo gairdneri Richardson. Fisheries Research Section, Fish and Wildlife Division, Alberta Energy and Natural Resources. Fisheries Research Report no. 14.

CHEVERUD, J. M., ROUTMAN, E. J., DUARTE, F. A. M., VAN SWINDEREN, B. ET AL. 1996. Quantitative trait loci for murine growth. Genetics, 142, 1305-1319.

CURRIE, R. J., BENNETT, w. A. AND BEITINGER, T. L. 1998. Critical thermal minima and maxima of three freshwater game-fish species acclimated to constant temperatures. Environ. Biol. Fishes, 51, 187-200.

DANZMANN, R. G., JACKSON, T. R. AND FERGUSON, M. M. 1999. Epistasis in allelic expression at upper temperature tolerance QTL in rainbow trout. Aquaculture, 173, 45-58.

FEVOLDEN, S. E., ROED, K. H., FJALESTAD, K. T. AND STIEN, J. 1999. Poststress levels of lysozyme and cortisol in adult rainbow trout: Heritabilities and genetic correlations. J. Fish Biol., 54, 900-910.

FRY, E. J. 1971. The effect of environmental factors on the physiology of fish. In: Hoar, W. S. and Randall, D. J. (eds) Fish Physiology, pp. 1-98. Academic Press, New York.

GROSS, R. AND NILSSON, J. 1999. Restriction fragment length polymorphism at the growth hormone 1 gene in Atlantic salmon (Salmo salar L.) and its association with weight among the offspring of a hatchery stock. Aquaculture, 173, 73-80.

IHSSEN, P. E. 1986. Selection of fingerling rainbow trout for high and low tolerance to high temperature. Aquaculture, 57, 370.

IWAMA, G. K., THOMAS, P. T., FORSYTH, R. B. AND VIJAYAN, M. M. 1998. Heat shock protein expression in fish. Rev. Fish Biol. Fish., 8, 35-56.

JACKSON, T. R., FERGUSON, M. M., DANZMANN, R. G., FISHBACK, A. G. $E T A L$. 1998. Identification of two QTL influencing upper temperature tolerance in rainbow trout (Oncorhynchus mykiss). Heredity, 80, 143-151.
JOHNSON, K. R., WRIGHT, J. E. JR AND MAY, B. 1987. Linkage relationships reflecting ancestral tetraploidy in salmonid fish. Genetics, 116, 579-591.

JOHnston, A. A. AND BENNETT, A. F. 1996. Animals and Temperature: Phenotypic and Evolutionary Adaptation. Society for Experimental Biology Seminar Series 59. Cambridge University Press, Cambridge, U.K.

KNOTT, S. A., MARKLUND, L., HALEY, C. S., ANDERSSON, K. ET $A L$. 1999. Multiple marker mapping of quantitative trait loci in a cross between outbred wild boar and Large White pigs. Genetics, 149, 1069-1080.

LIU, B. H. 1998. Statistical Genomics: Linkage, Mapping, and QTL Analysis. CRC Press, Boca Raton, Florida.

LYNCH, M. AND WALSh, B. 1998. Genetics and Analysis of Quantitative Traits. Sinauer Associates, Sunderland, MA.

MORIMOTO, R. I., TISSIÈRES, A. AND GEORGOPOULOS, C. 1994. The Biology of Heat Shock Proteins and Molecular Chaperones. Cold Spring Harbor Press Series 26, New York.

PALTI, Y., PARSONS, J. E. AND THORGAARD, G. H. 1999. Identification of candidate DNA markers associated with IHN virus resistance in backcrosses of rainbow (Oncorhynchus mykiss) and cutthroat trout (O. clarki). Aquaculture, 173, 81-94.

PENNell, w. AND BARTon, B. A. 1996. Principles of Salmonid Culture. Developments in Aquaculture and Fisheries Science, Vol. 29. Elsevier Science, New York.

POOMPUANG, S. AND HALLERMAN, E. M. 1996. Toward detection of quantitative trait loci and marker-assisted selection in fish. Rev. Fish. Sci., 5, 253-277.

POTTINGER, T. G. AND PICKERING, A. D. 1997. Genetic basis to the stress response: selective breeding for stress-tolerant fish. In: Iwama, G. K., Pickering, A. D., Sumpter, J. P. and Schreck, C. B. (eds) Fish Stress and Health in Aquaculture. Society for Experimental Biology Seminar Series 62, pp. 171-193. Cambridge University Press, Cambridge, U.K.

RICE, W. R. 1989. Analyzing tables of statistical tests. Evolution, 43, 223-225.

SAKAMOTO, T., DANZMANN, R. G., OKAMOTO, N., FERGUSON, M. M. $E T A L$. 1999. Linkage analysis of quantitative trait loci associated with spawning time in rainbow trout (Oncorhynchus mykiss). Aquaculture, 173, 33-43.

SAKAMOTO, T., DANZMANN, R. G., GHARBI, K., HOWARD, P. ET $A L$. 2000. A microsatellite linkage map of rainbow trout (Oncorhynchus mykiss) characterized by large sex-specific differences in recombination rates. Genetics, 155, 1331-1445.

SAS INSTITUTE. 1996. SAS, version 6.12. SAS Institute Inc., Cary, NC.

SHAPIRO, S. S. AND WILK, M. B. 1965. An analysis of variance test for normality (complete samples). Biometrika, 52, 591-611.

STEEL, R. G. D. AND TORRIE, J. H. 1980. Principles and Procedures of Statistics: A Biometrical Approach, 2nd edn. McGrawHill, New York.

STONE, R. T., KEELE, J. W., SHACKELFORD, S. D., KAPPER, S. M. ET $A L$. 1999. A primary screen of the bovine genome for quantitative trait loci affecting carcass and growth traits. J. Anim. Sci., 77, 1379-1384.

WOOD, C. M. AND McDONALD, D. G. 1997. Global warming: Implications for freshwater and marine fish. Society for Experimental Biology Seminar Series 61. Cambridge University Press, Cambridge, U.K. 